(c) American Dairy Science Association, 2003.

\title{
Hypocalcemia Reduces Endogenous Glucose Production in Hyperketonemic Sheep
}

\author{
C. Schlumbohm and J. Harmeyer \\ Department of Physiology \\ School of Veterinary Medicine \\ Bischofsholer Damm 15/102 \\ 30173 Hannover \\ Germany
}

\section{ABSTRACT}

In previous experiments it has been shown that hyperketonemia lowered plasma glucose concentration in sheep and depressed endogenous glucose production by approximately $30 \%$. This facilitates the onset of pregnancy toxemia. In the last trimester of gestation, hyperketonemia in sheep is often associated with hypocalcemia. There is an indication that hypocalcemia exerts an additional depressive effect on endogenous glucose production. The present study was undertaken to examine the effect in sheep of hypocalcemia on endogenous glucose production in the presence of normo- and hyperketonemia. The experiments were carried out with seven multiparous sheep during three different reproductive states, i.e., during pregnancy ( $10 \pm 8 \mathrm{~d}$ prepartum), during lactation ( $21 \pm 8 \mathrm{~d}$ postpartum), and $4 \mathrm{wk}$ after weaning of the lambs. Concentration of glucose in plasma, turnover of glucose and the rate constant of glucose turnover were measured by isotope dilution during normo- and hypocalcemia and in the presence of normal and elevated $\beta$-hydroxybutyrate (BHB) concentrations. Hypocalcemia was induced by i.v. infusions of $\mathrm{Na}_{2}$ EDTA. Hyperketonemia was maintained by i.v. infusion of DL- $\beta$-hydroxybutyrate. The experiments showed that induction of hypocalcemia: 1) induced a decline in plasma glucose concentration in all reproductive states during normo- and hyperketonemia and 2) significantly lowered endogenous production of glucose in nonpregnant hyperketonemic and in lactating normoketonemic ewes. Pregnant normoketonemic ewes were able to compensate for the hypoglycemic effect of hypocalcemia and to keep endogenous production at the normocalcemic level. We concluded that hypocalcemia does not promote the onset of pregnancy toxemia per se but will facilitate the development of the disease when it is present in combination with hyperketonemia.

Received September 2, 2002

Accepted December 2, 2002.

Corresponding author: Christina Schlumbohm; e-mail: christina. schlumbohm@tiho-hannover.de.
(Key words: Ca2+, glucose, sheep, ketosis)

Abbreviation key: D-BHB $=\mathrm{D}$ - $\beta$-hydroxybutyrate, DL-BHB $=$ DL- $\beta$-hydroxybutyrate, $\mathbf{i C a}=$ ionized calcium, $\mathbf{M E}=$ metabolizable energy.

\section{INTRODUCTION}

Previous experiments have shown that elevated ketone body concentrations in the plasma of sheep reduced endogenous glucose production by approximately $30 \%$ (Schlumbohm and Harmeyer, accepted). Furthermore, it was demonstrated in pigs with inherited hypocalcemia that a low plasma calcium concentration exerted an additional depressive effect on endogenous glucose production in the presence of hyperketonemia (Schlumbohm and Harmeyer, 1999). A low plasma calcium concentration (Twardock et al., 1973; Henze et al., 1994) accompanied by an elevated concentration of ketone bodies may also be observed in sheep during late pregnancy. Limitation of the availability of glucose is often regarded as a crucial factor for the development of ovine pregnancy toxemia (Wastney et al., 1983). It was therefore of interest to investigate in sheep the combined influences of hyperketonemia and hypocalcemia on endogenous glucose production and to see whether such a metabolic condition can facilitate development of pregnancy toxemia.

Ovine pregnancy toxemia frequently develops during the last 4 to $6 \mathrm{wk}$ of gestation, primarily in pregnancies with more than one fetus. About $60 \%$ of fetal growth takes place in this last gestation period (Twardock et al., 1973), and during this time approximately 33 to $36 \%$ of the circulating glucose is directed into the fetoplacental unit to satisfy its energetic demands (Hay et al., 1983). Hyperketonemia usually develops when, for yet unknown reasons, the capacity of maternal endogenous glucose production cannot cope with the increased demand of glucose, which is present in the pregnant ewe. During the last trimester of pregnancy, the growing fetus also retains an increasing amount of calcium from the circulation, which is required for skeletal de- 
velopment. The maternofetal drain of calcium across the placenta takes place by active transport in the presence of a concentration gradient (Care, 1997). Due to the fetal need of calcium, the calcium requirement of the ewe reaches its maximum at the end of pregnancy (Braithwaite et al., 1970). In most sheep this results in a negative calcium balance during late pregnancy (Braithwaite et al., 1970) and is often associated with a significant fall in the plasma Ca concentration (Twardock et al., 1973; Henze et al., 1994). Ewes that carry twins are in even greater need of calcium and are at the same time at a higher risk of developing pregnancy toxemia than ewes with only one offspring. Ovine pregnancies with more than one fetus are in fact more often accompanied with hypocalcemia and pregnancy toxemia than those with one lamb. About $50 \%$ of pregnant ewes in late pregnancy show a total calcium concentration in blood plasma below $2.1 \mathrm{mmol} \cdot \mathrm{L}^{-1}$ (Henze et al., 1994). In contrast, healthy nonpregnant ewes possess $\mathrm{Ca}$ concentrations in plasma of about $2.5 \mathrm{mmol} \cdot \mathrm{L}^{-1}$ (Henze et al., 1994). This raises the question as to what extent calcium deficiency during late pregnancy affects glucose metabolism and may facilitate development of pregnancy toxemia.

Indirect support for an involvement of hypocalcemia in the metabolism of glucose came from observations with high yielding dairy cows. At peak lactation such animals are also often in negative calcium balance with low calcium concentrations in plasma (Eldon, et al., 1988). At the same time they are at a higher risk of developing bovine ketosis. In fact, from epidemiological studies it was suggested that lactating cows with low plasma Ca concentrations more often develop bovine ketosis than animals with normal calcium concentrations (Bendixen et al., 1987). Our own previous experiments with hypocalcemic hyperketonemic piglets showed for the first time that hypocalcemia depressed endogenous glucose production (Schlumbohm and Harmeyer, 1999). Based on these results we were interested to see whether a similar depressive effect of hypocalcemia on glucose production is also present in sheep and may play a role in the development of pregnancy toxemia. In the present study, the kinetics of glucose metabolism were measured in normo- and hypocalcemic sheep in the presence and in the absence of hyperketonemia during three different reproductive states.

\section{MATERIALS AND METHODS}

\section{Chemicals}

D-2- $\left[{ }^{3} \mathrm{H}\right]$ glucose was used to assess kinetic parameters of glucose metabolism. It was purchased from $\mathrm{Du}$ Pont de Nemours (Dreieich, Germany). Na-DL- $\beta$ hydroxybutyrate was synthesized as described pre- viously (Schlumbohm and Harmeyer, 1999). The chemicals used for determination of the fraction of the D- $\beta$ hydroxybutyrate (D-BHB) isomer in the DL-racemate, were the same as described previously (Schlumbohm and Harmeyer, accepted). The D-isomer was measured in all infusate solutions and blood plasma. All other chemicals were purchased from Merck (Darmstadt, Germany) and were of analytical grade.

\section{Ethical Standards}

The animal experiments were approved by the ethical committee on animal rights protection of the Hannover District Government in accordance with German legislation on animal rights and welfare. In addition, Germany has signed and ratified the European convention for the protection of vertebrate animals used for experimental and other scientific purposes of March 18th 1986. The German legislation conforms in all respect with the requirements of this convention and guidelines prepared in pursuance of it.

\section{Experimental Animals}

Seven healthy nonketotic ewes were used for the study. They were purchased from a local breeder as pregnant in their third or a further pregnancy. This was the principal inclusion criterion. Three of the animals were Texel and four were German Blackheads. Both breeds are used equally for meat and wool production. They have the same reproduction rate of 1.5 lambs per ewe. Both breeds have the same average BW of 78 $\mathrm{kg}$. The animals were selected at random from these two breeds.

During the studies the animals showed no dysfunction of calcium metabolism (Table 1). The experiments were carried out on these seven sheep during three reproductive states, i.e., during late pregnancy (10 \pm 8 $\mathrm{d}$ prepartum), during early lactation ( $21 \pm 8 \mathrm{~d}$ postpartum), and in the nonpregnant nonlactating state (4 wk after weaning of the lambs). After weaning of the lambs one ewe died due to an infection and only six sheep remained for the measurements during the nonpregnant nonlactating state. The weight of the sheep ranged from 64 to $92 \mathrm{~kg}$ (Table 1). The stage of gestation and the number of fetuses in the pregnant animals were examined by ultrasonography. Three of the sheep had single fetuses and four carried twins. The sheep were kept indoors in groups and fed hay ad libitum. Water was accessible at all times. During the last 6 wk of pregnancy and during the first 6 wk of lactation the sheep were supplemented twice daily with concentrate feed (Club-Schafkraft, Club-Kraftfutterwerke Nord, Hamburg, Germany) containing $17 \%$ CP, $1.5 \%$ Ca, $0.5 \%$ 


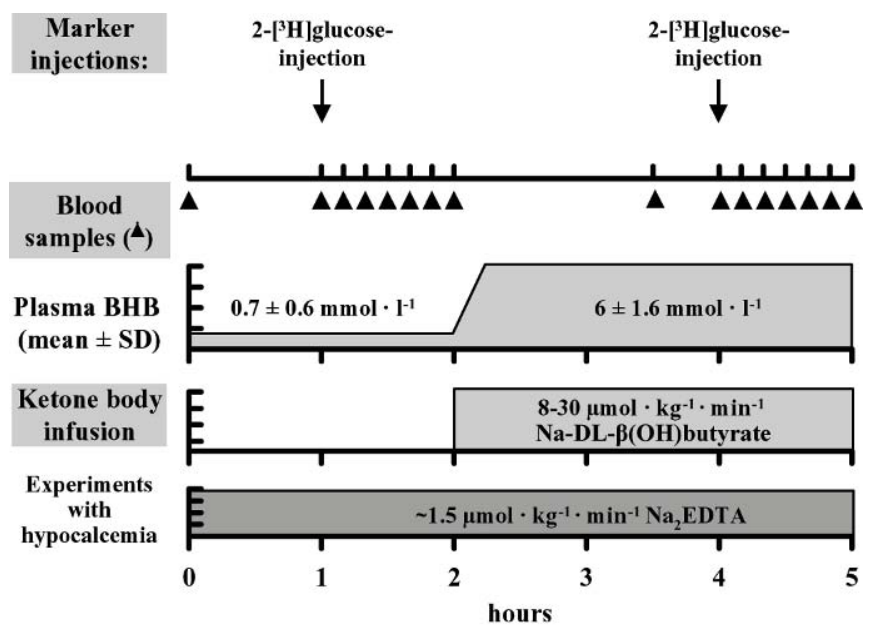

Figure 1. Schematic illustration of the experimental design. With each sheep two experiments were carried out a) during late pregnancy, b) during peak lactation, and c) after weaning of the lambs. In each reproductive state one experiment was in the presence of normocalcemia and one in the presence of hypocalcemia. At least 2 d elapsed between the two experiments. Each experiment comprised measurements during the normo- and during the hyperketonemia. (For details see text). The concentration of iCa was measured during the experiment in heparinised blood samples in 5- to 10-min intervals.

$\mathrm{P}$ and 10.2 MJ ME$\cdot \mathrm{kg}^{-1}$. Sheep that carried or suckled twins received $1000 \mathrm{~g}$ of concentrate per day and those with one offspring were fed $500 \mathrm{~g}$ of concentrate per day. The experiments were carried out after hay and concentrate had been withheld over night (for $12 \mathrm{~h}$ ). During the experiments the experimental animal and one companion animal were separated from the group and transferred into the laboratory. They were placed on a special rack. The study consisted of 40 experiments in total. One day before the experiment started, both jugular veins were catheterized (polyethylene tubing, i.d. $0.86 \mathrm{~mm}$ ). The catheters were filled with saline ( $0.9 \%$ weight per volume) containing 750 units $\cdot \mathrm{ml}^{-1}$ of heparin (Na-heparin, U.S.P. XXI, Roth, Karlsruhe, Germany) and were covered by a bandage around the neck. Body weights and hematological values from the beginning of the experiments are presented in Table 1.

\section{Experimental Design}

The experimental protocol is described in Figure 1. After an adaptation period of $1 \mathrm{~h}$, a bolus of $1.85 \mathrm{MBq}$ of D-2- $\left[{ }^{3} \mathrm{H}\right]$-glucose, dissolved in $5 \mathrm{ml}$ of a $10 \%$ glucose solution was intravenously injected. A second dose of $1.85 \mathrm{MBq}$ of $\mathrm{D}-2-\left[{ }^{3} \mathrm{H}\right]$-glucose was administered $3 \mathrm{~h}$ later to the sheep and $2 \mathrm{~h}$ after the beginning of a continuous intravenous DL-BHB infusion. This elevated the plasma $\mathrm{BHB}$ concentration from $0.73 \pm 0.38$ to $6.0 \pm 1.6 \mathrm{mmol} \cdot \mathrm{L}^{-1}$. Assignment of the samples to the 
Table 2. Protocol of glucose marker injections and assignment of plasma samples to various analyses.

\begin{tabular}{|c|c|c|c|c|c|c|c|c|c|c|c|c|c|c|c|c|c|}
\hline \multicolumn{2}{|c|}{ Time of sampling (min) } & 0 & 60 & 70 & 80 & 90 & 100 & 110 & 120 & 210 & 240 & 250 & 260 & 270 & 280 & 290 & 300 \\
\hline \multicolumn{2}{|c|}{$\mathrm{D}-2-\left[{ }^{3} \mathrm{H}\right]$-glucose marker injection } & & $\mathrm{X}$ & & & & & & & & $\mathrm{X}$ & & & & & & \\
\hline \multirow{3}{*}{$\begin{array}{l}\text { Measurements } \\
\text { carried out in } \\
\text { plasma samples }\end{array}$} & $\begin{array}{l}\text { D-BHB } \\
\left(\mathrm{mmol} \cdot \mathrm{l}^{-1}\right)\end{array}$ & $\mathrm{X}$ & & & & & & & & $\mathrm{X}$ & $\mathrm{X}$ & & & $\mathrm{X}$ & & & \\
\hline & $\begin{array}{l}\text { glucose } \\
\left(\mathrm{mmol} \cdot \mathrm{l}^{-1}\right)\end{array}$ & $\mathrm{X}$ & $\mathrm{X}$ & & $\mathrm{X}$ & & $\mathrm{X}$ & & $\mathrm{X}$ & & & & $\mathrm{X}$ & & $\mathrm{X}$ & & $\mathrm{X}$ \\
\hline & $\begin{array}{l}\mathrm{D}-2-\left[{ }^{3} \mathrm{H}\right] \text {-glucose } \\
\left(\mathrm{Bq} \cdot \mathrm{l}^{-1}\right)\end{array}$ & & & $\mathrm{X}$ & $\mathrm{X}$ & $\mathrm{X}$ & $\mathrm{X}$ & $\mathrm{X}$ & $\mathrm{X}$ & & & $\mathrm{X}$ & $\mathrm{X}$ & $\mathrm{X}$ & $\mathrm{X}$ & $\mathrm{X}$ & $\mathrm{X}$ \\
\hline
\end{tabular}

various analyses is listed in Table 2 . The experiments were carried out in the presence of a normal (1.27 \pm $\left.0.07 \mathrm{mmol} \cdot \mathrm{L}^{-1}, \bar{x} \pm \mathrm{SD}\right)$ and of a lowered $(0.93 \pm 0.03)$ plasma calcium concentration. At least $2 \mathrm{~d}$ were allowed for the sheep to recover from one experiment to the next. Hypocalcemia was induced by a continuous infusion of a $5 \% \mathrm{Na}_{2}$ EDTA solution (adjusted to $\mathrm{pH} 7.4$, filtered and autoclaved). The $\mathrm{Na}_{2}$ EDTA infusion rate was adjusted to achieve a concentration of iCa of $0.93 \pm 0.03$ $\mathrm{mmol} \cdot \mathrm{L}^{-1}(\bar{x} \pm \mathrm{SD}, \mathrm{n}=20$, Table 1$)$. The concentration of iCa was measured during the experiment in heparinised blood samples in 5- to 10-min intervals. These blood sampling times are not shown in Figure 1 and Table 2. When hypocalcemia was maintained for $1 \mathrm{~h}$ or in experiments with normocalcemia after an adaptation period of $1 \mathrm{~h}$, serial blood sampling was started. Each ewe received all four treatments at each stage of reproduction. Figure 2 presents a typical example of the temporal pattern of ionized calcium and BHB concentrations in plasma and of the calcium infusion rate over

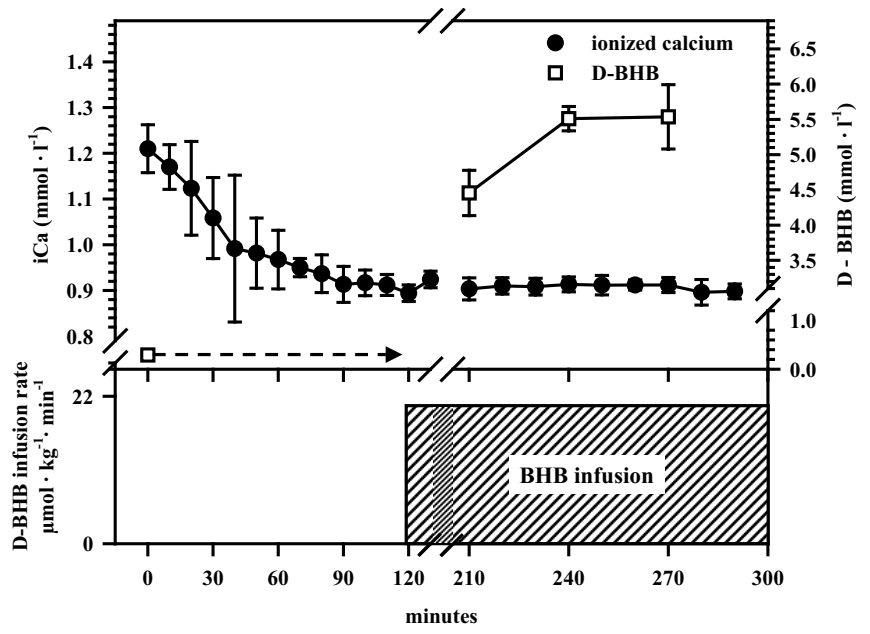

Figure 2. Temporal pattern of ionized $\mathrm{Ca}$ and $\mathrm{D}$ - $\beta$-hydroxybutyrate in blood plasma during experiments with hypocalcemia induced by continuous infusions of $\mathrm{Na}_{2}$-EDTA in nonpregnant, nonlactating ewes $(\mathrm{n}=6 ; \bar{x} \pm \mathrm{SD})$. the length of the experiment from hypocalcemic experiments.

\section{Laboratory Methods}

The applied laboratory methods were the same as described by Schlumbohm and Harmeyer (accepted). For determination of D-BHB in plasma, aliquots were deproteinized with $\mathrm{HClO}_{4}$. The supernatant was neutralized with $\mathrm{K}_{3} \mathrm{PO}_{4}$ and D-BHB was measured in the supernatant by the method of Williamson et al. (1962). The coefficient of variation was $4.6 \pm 3.9 \%(\bar{x} \pm \mathrm{SD}, \mathrm{n}=$ 160) for duplicate measurements with lower and upper limits of detection of 0.07 and $17 \mathrm{mmol} \cdot \mathrm{L}^{-1}$, respectively.

Glucose was determined with a reflection photometer (Reflolux, Roche Diagnostics, Mannheim, Germany). The glucose concentration measured with this method differed less than 5\% $(\mathrm{n}=40)$ from the photometrically determined concentration using the Glucose-Perid method (Roche Diagnostics, Mannheim, Germany). The coefficient of variation was $5.5 \%(\mathrm{n}=18)$ for duplicate measurements with lower and upper limits of detection of 1.1 and $22 \mathrm{mmol} \cdot \mathrm{L}^{-1}$, respectively. For measurement of D-2-[ $\left.{ }^{3} \mathrm{H}\right]$-glucose radioactivity in the plasma samples see Schlumbohm and Harmeyer (accepted).

Ionized calcium was determined in fresh blood samples with an ion sensitive electrode (Electrolyte Analyzer, AVL, Type 987-S, AVL Corp., Bad Homburg, Germany). The coefficient of variation was $1.43 \%(\mathrm{n}=25)$ for duplicate measurements with lower and upper limits of detection of 0.54 and $2.10 \mathrm{mmol} \cdot \mathrm{L}^{-1}$, respectively.

\section{Calculation of Glucose Turnover}

Turnover of glucose was calculated by a noncompartmental approach as described by Shipley and Clark (1972) and modified by Schlumbohm and Harmeyer (1999). The calculation consisted of two steps. First, the turnover of glucose per liter of glucose distribution volume $\left(\mathrm{mmol} \cdot \mathrm{L}^{-1} \mathrm{~min}^{-1}\right)$ was calculated by dividing the extrapolated radioactivity concentration of glucose at zero time $(\mathrm{A})_{0}\left(\mathrm{~Bq} \cdot \mathrm{L}^{-1}\right)$ by the $\mathrm{AUC}$ of the specific radio- 
activity vs. time curve $\left(\mathrm{Bq} \cdot \mathrm{mmol}^{-1} \cdot \mathrm{min}\right)$. This value is independent from the injected dose and from the time of first sampling of blood plasma. It is also not influenced by possible changes of the glucose space that might occur during the sampling period. In the second step the turnover of glucose per liter of glucose distribution volume obtained in the first calculation step was multiplied with the fractional distribution volume of

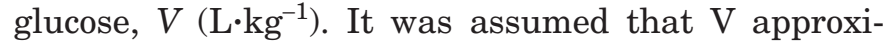
mately equals the extra cellular volume. This can be estimated by dividing the injected dose of marker $(\mathrm{Bq})$ by the extrapolated radioactivity concentration at zero time $(\mathrm{A})_{0}\left(\mathrm{~Bq} \cdot \mathrm{L}^{-1}\right)$ and the bodyweight of the sheep. The carryover of tracer from the first to the second $\left[{ }^{3} \mathrm{H}\right]-$ glucose injection $(=100 \%)$ amounted to $5.9 \pm 6.7 \%(\bar{x} \pm$ $\mathrm{SD})$. This carryover of radioactivity was taken into account when the glucose turnover from the second $\left[{ }^{3} \mathrm{H}\right]-$ glucose injection was calculated. The AUC between 4 and $8 \mathrm{~h}$ from the first $\left[{ }^{3} \mathrm{H}\right]$-glucose injection was estimated from the extrapolated radioactivity vs. time curve. This value was subtracted from the AUC between 4 to $8 \mathrm{~h}$ of the second $\left[{ }^{3} \mathrm{H}\right]$-glucose injection. The following abbreviations were used for the calculation.

\section{Abbreviations Used for Calculation of Glucose Kinetics:}

The following abbreviations were used in this study for calculation of glucose kinetics

$$
\begin{aligned}
& \mathrm{A}=\left[{ }^{3} \mathrm{H}\right] \text {-radioactivity per } \mathrm{ml} \text { blood plasma } \\
& {\left[\mathrm{Bq} \cdot \mathrm{L}^{-1}\right]} \\
& (\mathrm{A})_{t}=\left[{ }^{3} \mathrm{H}\right] \text {-radioactivity per ml blood plasma } \\
& \text { at any time }\left[\mathrm{Bq} \cdot \mathrm{L}^{-1}\right] \\
& \mathrm{C}=\text { concentration of glucose in blood } \\
& {\left[\mathrm{mmol} \cdot \mathrm{L}^{-1}\right]} \\
& (C)_{t}=\text { concentration of glucose in blood at } \\
& \text { any time }\left[\mathrm{mmol} \cdot \mathrm{L}^{-1}\right] \\
& \mathrm{SA}=\text { specific radioactivity of glucose } \\
& {\left[\mathrm{Bq} \cdot \mathrm{mmol}^{-1}\right]} \\
& (\mathrm{SA})_{\mathrm{t}}=\text { specific radioactivity at any time } \\
& {\left[\mathrm{Bq} \cdot \mathrm{mmol}^{-1}\right]} \\
& \mathrm{AUC}=\text { area } \text { under the }(\mathrm{SA})_{\mathrm{t}} \text { vs. time curve } \\
& {\left[\mathrm{Bq} \cdot \mathrm{mmol}^{-1} \cdot \mathrm{min}\right]}
\end{aligned}
$$

The $(\mathrm{SA})_{t}$ of glucose was obtained by dividing the radioactivity of glucose per unit volume by the glucose concentration:

$$
(\mathrm{SA})_{\mathrm{t}}\left[\mathrm{Bq} \cdot \mathrm{mmol}^{-1}\right]=\frac{(A)_{t}}{(C)_{t}} \frac{\left[B q \cdot L^{-1}\right]}{\left[\mathrm{mmol} \cdot \mathrm{L}^{-1}\right]}
$$

The glucose concentration in blood plasma before and during the DL-BHB infusion periods fluctuated by 4.6 $\pm 3.0 \%(\bar{x} \pm \mathrm{SD})$. The $\mathrm{D}-2-\left[{ }^{3} \mathrm{H}\right]$-glucose radioactivity per $\mathrm{ml}$ plasma was divided by the mean glucose concentration present during the corresponding sampling period.

The curve of (SA) $t$ was mathematically extrapolated to $t_{0}$, (the time of marker injection) and to a cutoff point beyond $60 \mathrm{~min}$, for which the marker concentration was $<1 \%$ of $(\mathrm{SA})_{0}$. This time equaled about $240 \mathrm{~min}$. For extrapolation of $(\mathrm{SA})_{t}$ and estimation of the coefficients $\left(\mathrm{E}_{1}, \mathrm{E}_{2}\left[\mathrm{~Bq} \cdot \mathrm{mmol}^{-1}\right]\right)$ and the exponents $\left(\mathrm{k}_{1}, \mathrm{k}_{2}\left[\mathrm{~min}^{-1}\right]\right)$, the measured values were fitted to a two exponential equation $\left(F_{t}\right)$ of the form:

$$
(\mathrm{SA})_{\mathrm{t}}\left[\mathrm{Bq} \cdot \mathrm{mmol}^{-1}\right]=\mathrm{E}_{1} \exp \left(-\mathrm{k}_{1} \mathrm{t}\right)+\mathrm{E}_{2} \exp \left(-\mathrm{k}_{2} \mathrm{t}\right)
$$

using the program Sigmaplot (SPSS Science Software Scientific, Erkrath, Germany). For further details see Schlumbohm and Harmeyer (accepted). The (SA) from 0 to 240 min was used to calculate the area under the curve (AUC).

The turnover of glucose in one liter of its distribution volume (normalized glucose turnover) was calculated by dividing the extrapolated value $(\mathrm{A})_{0}$ by $\mathrm{AUC}$ :

$$
\begin{aligned}
& \text { normalized glucose turnover }\left[\mathrm{mmol} \cdot \mathrm{L}^{-1} \cdot \mathrm{min}^{-1}\right] \\
& \qquad=\frac{(A)_{0}}{A U C} \frac{\left[B q \cdot L^{-1}\right]}{\left[B q \cdot \mathrm{mmol}^{-1} \cdot \mathrm{min}\right]}
\end{aligned}
$$

The turnover of glucose per unit body weight per minute $\left[\mathrm{mmol} \cdot \mathrm{kg}^{-1} \cdot \mathrm{min}^{-1}\right]$ was estimated from the normalized glucose turnover by multiplying the normalized glucose turnover with the fractional distribution volume of glucose (V) $\left[\mathrm{L} \cdot \mathrm{kg}^{-1}\right]$. (V) was calculated by dividing the injected dose of marker $[\mathrm{Bq}]$ by the extrapolated marker concentration at zero time $\left[\mathrm{Bq} \cdot \mathrm{L}^{-1}\right]$ and by the body weight of the ewe [kg].

$$
\mathrm{V}\left[{\left.\mathrm{L} \cdot \mathrm{kg}^{-1}\right]}^{-1}=\frac{\text { dose of marker }}{(A)_{0} \cdot B W} \frac{[B q]}{\left[B q \cdot L^{-1}\right] \cdot[k g]}\right.
$$

The rate constant of glucose turnover was calculated by dividing $(\mathrm{SA})_{0}$ by AUC.

$$
\text { rate constant }\left[\mathrm{min}^{-1}\right]=\frac{(S A)_{0}}{A U C} \frac{\left[B q \cdot \mathrm{mmol}^{-1}\right]}{\left[B q \cdot \mathrm{mmol}^{-1} \cdot \mathrm{min}\right]}
$$

For further details of the calculation see Schlumbohm and Harmeyer (1999). 


\section{Statistics}

The parameters for glucose metabolism were tested in a one-way ANOVA for the presence of significant differences between animals. No significant differences existed between animals. The parameters of glucose kinetics were then tested as repeated measures (RM) for the presence of significant effects of hypocalcemia and hyperketonemia. The statistical analysis showed that the original data groups were normally distributed, but the differences between data pairs used for significance testing were not. The calcium and BHB effects were therefore examined by a nonparametric test in a one-way RM ANOVA on ranks with 12 different conditions. These conditions comprised four conditions in each reproductive state, i.e., normo- and hypocalcemia, each during normo- and hyperketonemia. This statistical approach provided no information on any interactions between calcium and BHB. An estimate of such interactions was obtained from the distribution of significant differences among combinations of the 12 conditions. This analysis did not indicate significant interactions between any of the reproductive states and the two calcium conditions and between any of the reproductive states and the two BHB conditions. This analysis also indicated that the influence of $\mathrm{BHB}$ on parameters of glucose metabolism irrespective of the calcium concentration was more highly significant than the influence of calcium (irrespective of the BHB concentration). The Student-Newman-Keuls test was used to evaluate significant differences between group pairs. The statistical program SigmaStat (SPSS Science Software Scientific, Erkrath, Germany) was used for the calculations. Since the original data sets are normally distributed these values are presented in the figures as arithmetic means \pm SD.

\section{RESULTS}

\section{Influence of Hypocalcemia on Glucose Metabolism in Animals with Normal Concentration of Ketone Bodies in Plasma}

Hypocalcemia had no significant effect on the plasma glucose concentration, but compared to normocalcemia it lowered the mean concentration in all three reproductive states (Figure 3A).

Hypocalcemia significantly elevated the rate constant of glucose turnover in nonpregnant nonlactating sheep, and compared to normocalcemia it tended to elevate the mean values in all three reproductive states (Figure 4A).

Hypocalcemia significantly reduced glucose turnover in nonpregnant lactating sheep but had no effect in the other two reproductive states (Figure 5A).

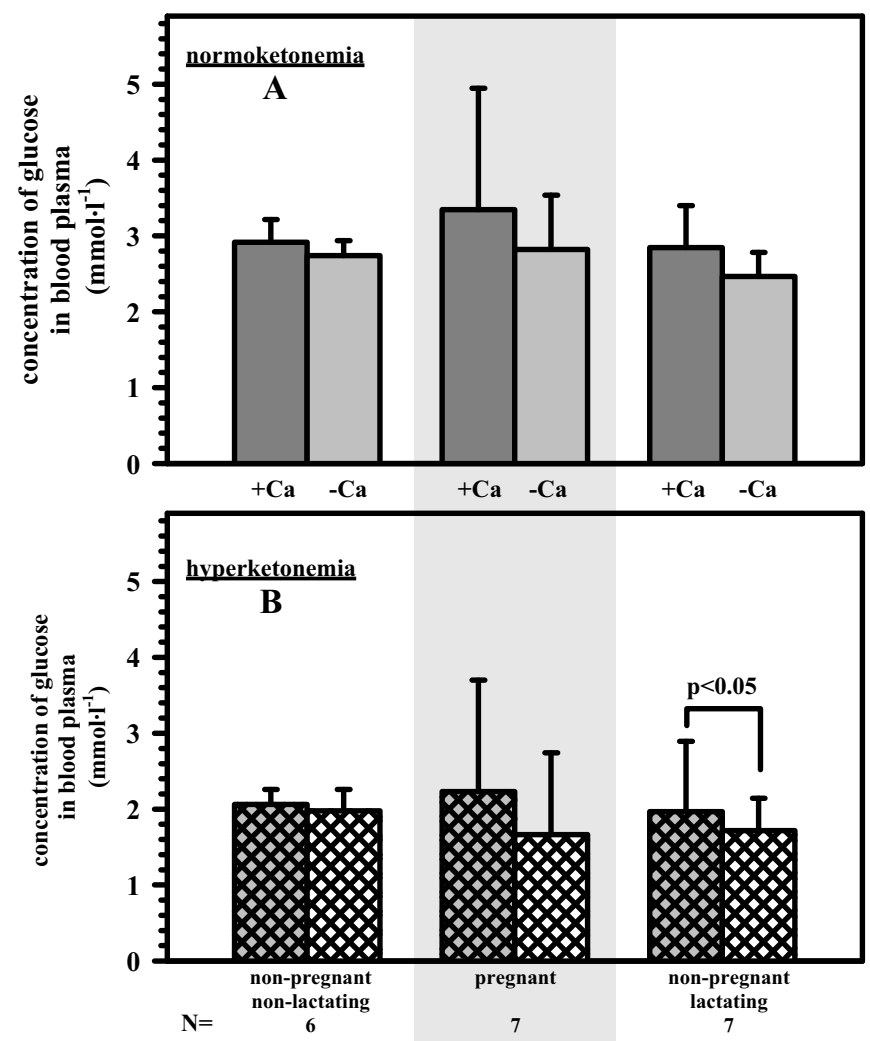

Figure 3. Concentration of glucose in plasma of normo- and hypocalcemic ewes in the presence of normal (A) and elevated (B) BHB concentrations in plasma during three reproductive states $(\bar{x} \pm \mathrm{SD})$.

\section{Influence of Hypocalcemia on Glucose Metabolism in Animals with Elevated Concentration of Ketone Bodies in Plasma}

Hypocalcemia lowered significantly the plasma glucose concentration in nonpregnant lactating ewes compared to normocalcemia and showed the same trend in the other two reproductive states (Figure 3B).

Hypocalcemia showed no significant effect on the rate constants of glucose turnover. The mean values tended to decline in the nonpregnant states and tended to increase in the pregnant state (Figure 4B).

Hypocalcemia significantly reduced glucose turnover in nonpregnant sheep and showed no effect in pregnant ewes (Figure 5B).

\section{Influence of Hyperketonemia on Parameters of Glucose Metabolism in the Presence of Normal and Lowered Calcium Concentrations in Plasma}

In earlier experiments with sheep it had been shown that an elevation of the BHB concentration in plasma significantly depressed glucose concentration (Schlumbohm and Harmeyer, accepted). The present study 

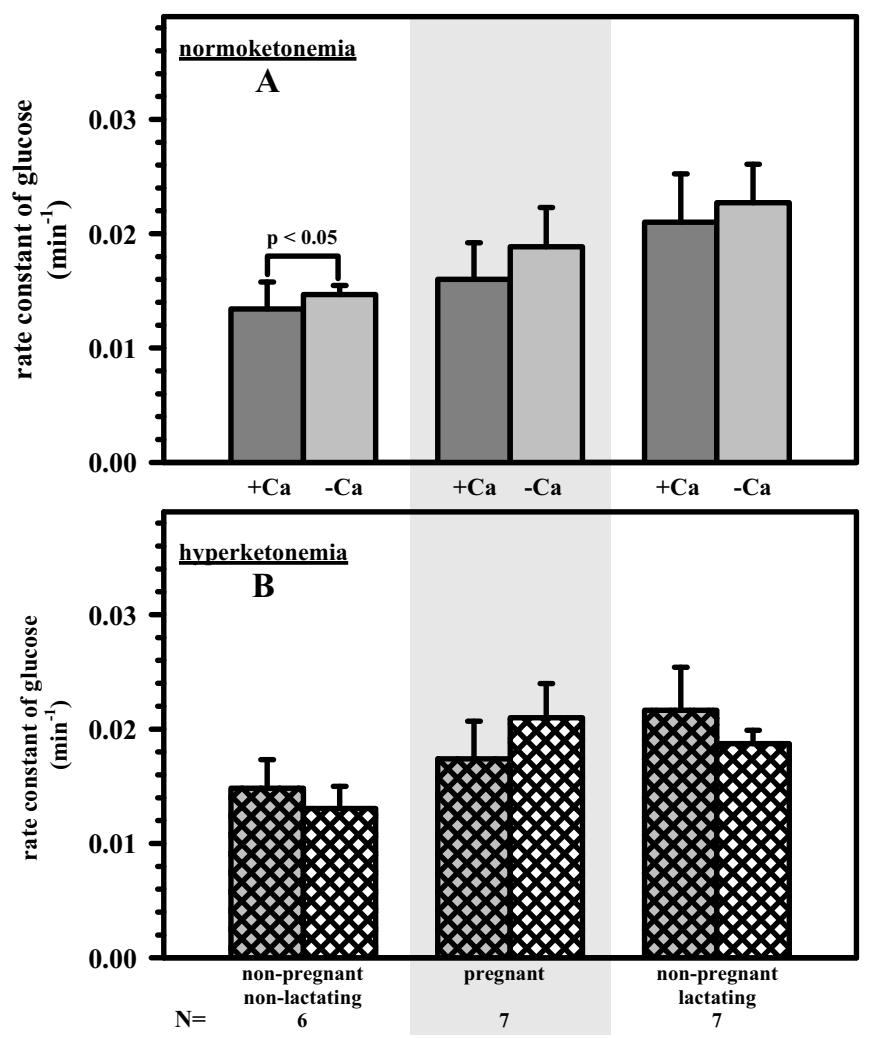

Figure 4. Rate constants of glucose turnover in normo- and hypocalcemic ewes in the presence of normal (A) and elevated (B) BHB concentrations in plasma during three reproductive states $(\bar{x} \pm \mathrm{SD})$.

shows that this depressive effect is also present in hyperketonemic hypocalcemic sheep (Table 3). The percentage decline in glucose concentration due to hyperketonemia was about the same in normo- and in hypocalcemic sheep and it was present throughout the three reproductive states (Table 3 ). The rate constants of glucose turnover were significantly elevated by hyperketonemia in normocalcemic nonpregnant nonlactating sheep and were significantly depressed in hypocalcemic nonpregnant nonlactating sheep (Table 3).

Glucose turnover was significantly depressed by hyperketonemia in all reproductive states (Table 3). This reduction was greater in hypocalcemic than in normocalcemic ewes.

\section{DISCUSSION}

\section{General Remarks}

To our knowledge this study is the first to show that hypocalcemia in sheep significantly depresses endogenous glucose production. Hypocalcemia is frequently observed in ewes during late pregnancy (Twardock et al., 1973). The decline of the plasma calcium concentra-

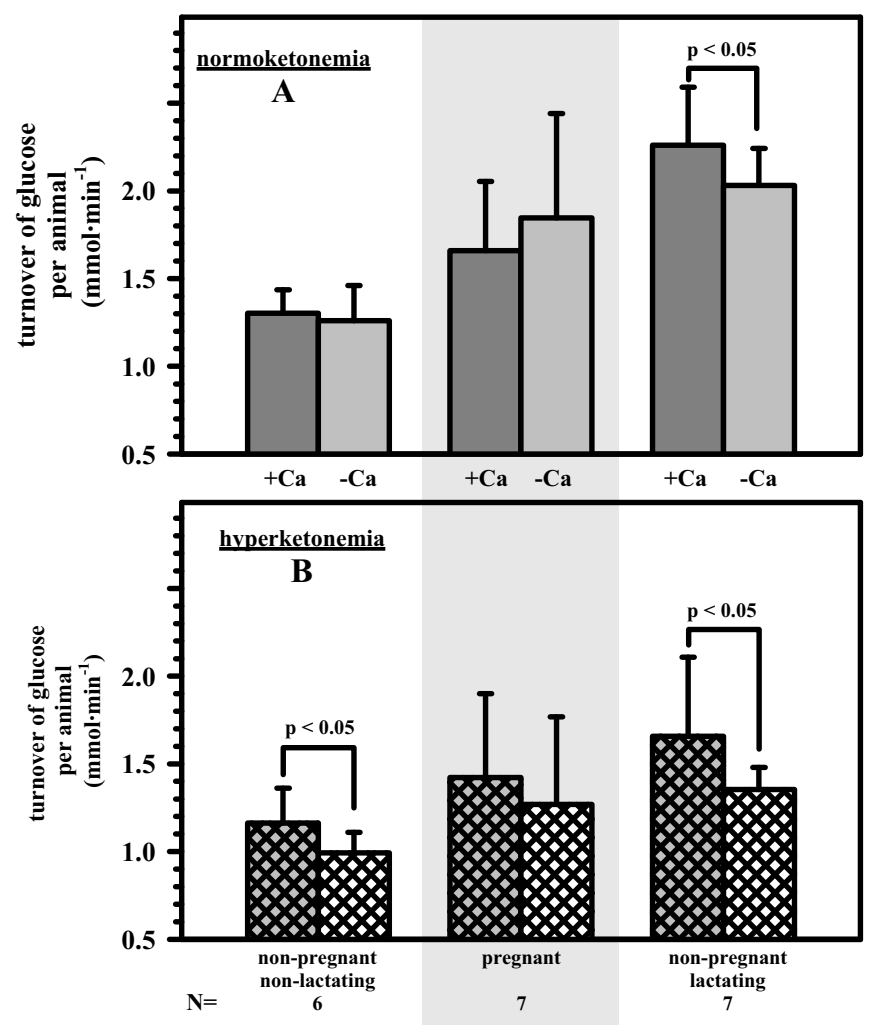

Figure 5. Turnover of glucose in normo- and hypocalcemic ewes in the presence of normal (A) and elevated (B) BHB concentrations in plasma during three reproductive states $(\bar{x} \pm \mathrm{SD})$.

tion probably facilitates the onset of pregnancy toxemia. For interpretation of the present findings it has to be kept in mind that under steady state conditions the appearance rate of glucose equals its rate of disappearance. Measurement of glucose turnover during a steady state by isotope dilution provides an estimate of its appearance rate and its disappearance rate. The rate constant of glucose turnover constitutes a quantitative measure of all mechanisms that eliminate glucose from the glucose-sampling compartment of the body. If the rate constant of glucose turnover would increase and the appearance rate of glucose (endogenous glucose production) would remain unchanged the plasma glucose concentration would fall. If the rate constant of glucose turnover would remain constant and the appearance rate of glucose turnover would decline the plasma glucose concentration would also fall. We believe that in our study the animals were in a postabsorptive state. Glucose entry from the GI tract had probably dropped to almost zero 12 to $18 \mathrm{~h}$ after the last meal. We assume that the values of glucose turnover we were measuring were estimates of endogenous glucose production and peripheral utilization of glucose. The animals were accustomed to the experimental conditions and were re- 
Table 3. Concentration of glucose in blood plasma, rate constants of glucose turnover and turnover of glucose in hyperketonemic sheep during normo- and hypocalcemia presented as percent values. The corresponding normoketonemic values $=100 \%, \bar{x} \pm$ SD.

\begin{tabular}{|c|c|c|c|c|c|c|}
\hline \multirow[b]{3}{*}{ Calcemia } & \multicolumn{6}{|c|}{ Reproductive state } \\
\hline & \multicolumn{2}{|c|}{$\begin{array}{l}\text { Nonpregnant } \\
\text { nonlactating } \\
\mathrm{n}=6\end{array}$} & \multicolumn{2}{|c|}{$\begin{array}{c}\text { Pregnant } \\
\mathrm{n}=7\end{array}$} & \multicolumn{2}{|c|}{$\begin{array}{l}\text { Lactating } \\
\mathrm{n}=7\end{array}$} \\
\hline & normo & hypo & normo & hypo & normo & hypo \\
\hline Concentration of glucose in blood plasma (\%) & $71 \pm 10^{*}$ & $72 \pm 10^{*}$ & $64 \pm 18^{*}$ & $55 \pm 30^{*}$ & $68 \pm 30^{*}$ & $69 \pm 14^{*}$ \\
\hline Rate constant of glucose turnover (\%) & $112 \pm 15^{*}$ & $90 \pm 13^{*}$ & $110 \pm 18$ & $113 \pm 19$ & $105 \pm 21$ & $84 \pm 13$ \\
\hline
\end{tabular}

*Values with superscript are significantly different with $P<0.05$ from the corresponding value under normoketonemic conditions.

laxed while accompanied by a companion sheep. During the experiments the animals were not subjected to any physical stress.

The glucose concentrations in blood plasma which were determined in this study in normoketonemic normocalcemic sheep were in the same range than those reported in the literature, i.e. 3.24, 2.95, and 2.79 $\mathrm{mmol} \cdot \mathrm{L}^{-1}$ for healthy fed lactating $(\mathrm{n}=25)$, single pregnant $(\mathrm{n}=33)$ and twin pregnant $(\mathrm{n}=52)$ ewes, respectively (Henze et al., 1994). The same was true for the basal D-BHB concentrations which were also in the same range as the reported values: $0.6,0.32$, and 0.35 $\mathrm{mmol} \cdot \mathrm{L}^{-1}$, for healthy fed lactating, single pregnant, and twin pregnant ewes, respectively (Henze et al., 1994). Concentrations of ionized calcium of 1.16 and $1.38 \mathrm{mmol} \cdot \mathrm{L}^{-1}$ for pregnant and lactating sheep have been reported to be normal (Zepperitz and Guertler, 1992). This also agrees with our measurements.

\section{Possible Sequence of Events of Hypocalcemia on Glucose Metabolism}

a) In the presence of a normal concentration of ketone bodies. During normoketonemia induced hypocalcemia elevated the rate constant of glucose turnover (Figure 4) and lowered the plasma glucose concentration (Figure 3). From these effects only the increase of the rate constant of glucose turnover in nonpregnant nonlactating ewes was statistically significant but the mean values in all three reproductive states followed the same trend. Glucose turnover tended to decrease in nonpregnant sheep and remained unchanged in pregnant ewes (Figure 5). One explanation for this effect is, that hypocalcemia depressed endogenous glucose production. The reduced appearance rate of glucose resulted in a decrease of glucose concentration in plasma and in a decrease in the disappearance rate of glucose. The sheep responded to the reduction of available glucose by increasing the rate constant of glucose turnover. This response further decreases the plasma glucose concentration but perhaps exerts a stimulus on endogenous glucose production. Due to this stimulus the turnover of glucose in the presence of hypocalcemia remained essentially unchanged in nonpregnant nonlactating and in pregnant ewes and was only slightly lowered in lactating ewes (Figure 5). This glucose turnover was present, however, at a lower plasma glucose concentration combined with a higher rate constant of glucose turnover.

It appears that the pregnant ewes better compensated for the depressive action of hypocalcemia on endogenous glucose production than nonpregnant ewes. The mean values of glucose turnover remained unchanged under the normo- and hypocalcemic conditions. Nonpregnant sheep can probably compensate for a reduced availability of glucose by the provision of alternate fuels, such as fat or ketone bodies (Robinson and Williamson, 1980; Walker and Alberti, 1997). The pregnant ewe has less of an adaptive capability likely because much of the available glucose goes to the fetus. And the fetus relies much more on a constant supply of glucose than other body tissues (Morriss et al., 1974; Dalinghaus, 1991; Milley, 1993). We conclude from these findings that hypocalcemia imposes a greater regulatory and metabolic stress on pregnant sheep than on nonpregnant sheep. This assumption is supported by an observation of Bergman (Bergman et al., 1963; Bergman and Kon, 1964) who showed that in pregnant ewes $\mathrm{CO}_{2}$ production from ketone bodies accounted for maximally $20 \%$, but in nonpregnant ewes for $31 \%$ of total $\mathrm{CO}_{2}$ production.

Our study provides no information as to what mechanisms mediated the increase in the rate constant of glucose turnover in pregnant sheep and were responsible for the compensation of the depressive effect of hypocalcemia. Stimulation of the Glut1 and Glut3 mediated transport of glucose across the placenta requires either an increase in number of transporters or an increase in the transplacental concentration gradient (Bloch et al., 1986; Hay et al., 1989). The latter alternative can be excluded. This would require a significant fall in fetal plasma glucose concentration when the maternal 
plasma glucose concentration remains unchanged. An increase in the number of the glucose transporters could be brought about by endocrine pathways. Glucocorticoids have been shown to affect transplacental glucose transport in humans, rats and mice (Hahn et al., 1999; Langdown and Sugden, 2001). Glucocorticoid concentrations in plasma of pregnant ewes are relatively high (Basset, 1989; Henze et al., 1994) and increase in pregnant hypoglycemic ewes (Sasaki et al., 1974; Mellor et al., 1977; Owens et al., 1984).

b) In the presence of elevated concentrations of ketone bodies. The depressive effect of hypocalcemia on glucose metabolism in hyperketonemic sheep was essentially similar to that observed in normoketonemic sheep but appeared to be more pronounced. Hypocalcemia significantly depressed glucose turnover in pregnant sheep. During normoketonemia the rate constants of glucose turnover were partly significantly elevated or showed a trend in this direction. During hyperketonemia the sheep were apparently unable to respond to the depressive influence of hypocalcemia with an increase of the rate constants of glucose turnover. This inability resulted in a significant reduction of glucose turnover. Only hyperketonemic pregnant ewes appeared to be capable to effectively respond to the depressive effect of hypocalcemia, first by up regulation of the rate constant of glucose turnover and then by keeping the glucose turnover constant, but in the presence of a lower concentration of plasma glucose. The possible reasons for this adaptive response of the pregnant ewes have been discussed in the previous section. These observations are in agreement with results from our own previous studies which showed that glucose flux into peripheral tissues was decreased in hyperketonemic hypocalcemic piglets (Schlumbohm and Harmeyer, 1999). We conclude from these results that hypocalcemia exerts an extraregulatory strain upon the pregnant ewe.

c) Effect of Hyperketonemia on glucose metabolism. This study also provided further evidence that an elevated level of ketone bodies in plasma impairs glucose metabolism. This is the case, both, during normo- and hypocalcemia (Table 3). Elevation of BHB resulted in a significant drop in plasma glucose concentration and a significant decline of glucose turnover. This effect was present during all three reproductive states and was in accord with own previous findings which showed that elevation of the BHB concentration constituted a significant inhibitory factor on endogenous glucose production (Schlumbohm and Harmeyer, accepted). Hyperketonemia undoubtedly contributes to the onset of pregnancy toxemia. When it occurs in the presence of hypocalcemia the effects appear to be additive.
Information is also scarce about the possible mechanisms responsible for the hypoglycemic effects of high ketone body concentrations. Theoretically, insulin could be involved in this effect, but ketone bodies constitute only a weak stimulus for insulin secretion in ruminants (Jordan and Phillips, 1978; Heitmann and Fernandez, 1986). In our experiments, insulin appeared to play no significant role in mediating the lowering effect of ketone bodies on plasma glucose concentration. This was concluded from the observation that the rate constants of glucose turnover decreased during the BHB load (Table 3). One would expect them to increase if the plasma glucose concentration was reduced due to insulin. So, we believe that the decline in plasma glucose concentration during the BHB load was not mediated by insulin.

Irrespective of the underlying endocrine mechanisms, the following sequence of events may take place in the presence of combined hyperketonemia and hypocalcemia and may form a metabolic spiral which eventually leads to pregnancy toxemia:

a) Reduction of endogenous glucose production and limitation of the amount of available glucose,

b) decline of the plasma glucose concentration,

c) stimulation of the rate of lipolysis,

d) further elevation of the $\mathrm{BHB}$ concentration in plasma, and

e) further depression of glucose production with further stimulation of the rate of lipolysis.

It appears that a low plasma calcium concentration alone, which is often present in multiparous sheep during late pregnancy, does not greatly reduce glucose turnover and will probably not result in pregnancy toxemia provided the concentration of ketone bodies in plasma remains in its physiological range. Hypocalcemia exerts, however, an additional metabolic stress on the glucose homeostatic system of the pregnant ewe. Hyperketonemia on the other hand markedly depresses endogenous glucose production and diminishes the regulatory limits of the pregnant ewe. A combination of hyperketonemia and hypocalcemia facilitates the onset of pregnancy toxemia by exerting additive depressive effects upon the glucose homeostatic system.

It would be of interest to see whether hyperketonemia in concert with hypocalcemia is also active in dairy cows and function as additive risk factors for the development of bovine ketosis. Metabolic characteristics of bovine ketosis and ovine pregnancy toxemia possess many similarities. This is particularly true for the limitation of endogenous glucose production. Also, the combined effects of hyperketonemia and hypocalcemia in de- 
pressing endogenous glucose production in the sheep were basically the same during all reproductive states.

We believe that induction of hypocalcemia by $\mathrm{Na}_{2}$ EDTA had no adverse effect on parameters of glucose metabolism such as the glucose space (Jørgensen et al., 1999). The distribution volumes of glucose were $24.1 \pm$ $5.17 \%$ during hypocalcemia and $25.9 \pm 5.53 \%$ during normocalcemia. We think that the hypocalcemic effects on glucose metabolism measured in this study cannot be ascribed to the infusion of $\mathrm{Na}_{2}$ EDTA.

\section{ACKNOWLEDGMENTS}

This study was supported by the Deutsche Forschungsgemeinschaft, grant No HA 542/11-2.

\section{REFERENCES}

Basset, J. M. 1972. Plasma glucagon concentrations in sheep: Their regulation and relation to concentrations of insulin and growth hormone. Aust. J. Biol. Sci. 25:1277-1287.

Basset, J. M. 1983. Endocrine and metabolic responses to intravenous glucose or insulin injection in sheep during pregnancy and lactation. Proc. Nutr. Soc. 42:35A.

Basset, J. M. 1989. Metabolic and endocrine responses of pregnant and lactating ewes to intravenous glucose or insulin. J. Agr. Sci. 113:173-182.

Bendixen, P. H., D. Vilson, J. Ekesbo, and D. B. Astrand. 1987. Disease frequencies in dairy cows in sweden. IV Ketosis. Prev. Vet. Med. 5:99-109.

Bergman, E. N., and K. Kon. 1964. Acetoacetate turnover and oxidation rates in ovine pregnancy ketosis. Am. J. Physiol. 206:449453.

Bergman, E. N., K. Kon, and M. L. Katz. 1963. Quantitative measurement of acetoacetate metabolism and oxidation in sheep. Am. J. Physiol. 205:658-662.

Bloch, C. A., W. Banach, K. Landt, S. Devaskar, and M. A. Sperling. 1986. Effects of fetal insulin infusion on glucose kinetics in pregnant sheep: a compartmental analysis. Am. J. Physiol. 251:E448-E456.

Braithwaite, G. D., R. F. Glascock, and S. Riazuddin. 1970. Calcium metabolism in pregnant ewes. Br. J. Nutr. 24:661-670.

Care, A. D. 1997. Fetal calcium homeostasis. Equine Vet. J. 24 (Suppl.):59-61.

Dalinghaus, M., C. D. Rudolph, and A. M. Rudolph. 1991. Effects of maternal fasting on hepatic gluconeogenesis and glucose metabolism in fetal lambs. J. Dev. Physiol. 16:267-275.

Eldon, J., T. Thorsteinsson, and T. Olafsson. 1988. The concentration of blood glucose, urea, calcium and magnesium in milking dairy cows. Zentralbl. Veterinaermed. Reihe A 35:44-53.

Hahn, T., S. Barth, R. Graf, M. Engelmann, D. Beslagic, J. M. Reul, F. Holsboer, G. Dohr, and G. Desoye. 1999. Placental glucose transporter expression is regulated by glucocorticoids. J. Clin. Endocrinol. Metab. 84:1445-1452.

Hay, W. W., Jr., and H. K. Meznarich. 1989. Effect of maternal glucose concentration on uteroplacental glucose consumption and transfer in pregnant sheep. Proc. Soc. Exp. Biol. Med. 190:63-69.

Hay, W. W., Jr., J. W. Sparks, R. B. Wilkening, F. C. Battaglia, and G. Meschia. 1983. Partition of maternal glucose production between conceptus and maternal tissues in sheep. Am. J. Physiol. 245:E347-E350.

Heitmann, R. N., and J. M. Fernandez. 1986. Autoregulation of alimentary and hepatic ketogenesis in sheep. J. Dairy Sci. 69:1270-1281.

Henze, P., K. Bickhardt, and H. Fuhrmann. 1994. The influence of the hormones insulin, cortisol, growth hormone and total oestrogen on the pathogenesis of ketosis in sheep. Dtsch. tieraerztl. Wschr. 101:61-65.

Jordan, H. N., and R. W. Phillips. 1978. Effect of fatty acids on isolated ovine pancreatic islets. Am. J. Physiol. 234:E162-E167.

Jørgesen, R. J., N. R. Nyengaard, R. C. W. Daniel, L. S. B. Melau, and J. M. D. Enemark. 1999. Induced Hypocalcaemia by $\mathrm{Na}_{2}$ EDTA Infusion. A Review. J. Vet. Med. A 46:389-407.

Langdown, M. L., and M. C. Sugden. 2001. Enhanced placental Glut1 and Glut3 expression in dexamethasone-induced fetal growth retardation. Mol. Cell. Endocrinol. 185:109-117.

Mellor, D. J., I. C. Matheson, and J. Small. 1977. Some changes in the composition of maternal and fetal plasma from chronically catheterised sheep during short periods of reduced feed intake in late pregnancy. Res. Vet. Sci. 23:119-121.

Milley, J. R. 1993. Ovine fetal protein metabolism during decreased glucose delivery. Am. J. Physiol. 265:E525-E531.

Morriss, F. H., Jr., R. D. Boyd, E. L. Makowski, G. Meschia, and F. C. Battaglia. 1974. Umbilical V-A differences of acetoacetate and beta-hydroxybutyrate in fed and starved ewes. Proc. Soc. Exp. Biol. Med. 145:879-883.

Owens, P. C., R. Smith, D. Green, and L. Falconer. 1984. Effect of hypoglycemic stress on plasma and cerebrospinal fluid immunoreactive beta-endorphin in conscious sheep. Neurosci. Let. 49:1-6.

Robinson, A. M., and D. H. Williamson. 1980. Physiological roles of ketone bodies as substrates and signals in mammalian tissues. Physiol. Rev. 60:143-187.

Sasaki, Y., K. Kumazaki, and O. Ikeda. 1974. Relationship between plasma glucocorticoids and the maintenance of blood glucose level in the fasted animal. Jap. J. Zootech. Sci. 45:81-87.

Schlumbohm, C., and J. Harmeyer. 1999. Effect of hypocalcaemia on glucose metabolism in hyperketonaemic piglets. Exp. Physiol. 84:707-723.

Schlumbohm, C. and J. Harmeyer. 2002. Hyperketonemia impairs glucose metabolism in ewes. J. Dairy Sci. (accepted).

Shipley, R. A., and R. E. Clark. 1972. Tracer methods for in vivo kinetics, theory and applications. Pages 93-109. Academic Press, New York.

Twardock, A. R., H. W. Symonds, B. F. Sansom, and G. J. Rowlands. 1973. The effect of litter size upon foetal growth rate and the placental transfer of calcium and phosphorus in superovulated Scottish half-bred ewes. Br. J. Nutr. 29:437-447.

Walker, M., and K. G. M. M. Alberti. 1997. Insulin actions in vivo: Role in the regulation of ketone bodies. Pages 541-547 in International Textbook of Diabetes Mellitus. 2nd ed. K. G. Alberti, M. M. P. Zimmet, R. A. DeFronzo, and H. Keen, ed. John Wiley \& Sons Ltd, United Kingdom.

Wastney, M. E., J. E. Wolff and R. Bickerstaffe. 1983. Glucose turnover and hepatocyte glucose production of starved and toxaemic pregnant sheep. Aust. J. Biol. Sci. 36:271-284.

Williamson, D. H., J. Mellanby, and H. A. Krebs. 1962. Enzymatic determination of $\mathrm{D}(-)-$ beta-hydroxybutyric acid and acetoacetic acid in blood. Biochem. J. 82:90-96.

Wollheim, C. B., and G. W. Sharp. 1981. Regulation of insulin release by calcium. Physiol. Rev. 61:914-973.

Zepperitz, H. and H. Guertler. 1992. Ionized calcium and total calcium in the blood of cattle, sheep, swine and horses of different ages, reproductive stages and uses. Berl. Muench. Tieraerzt. Wochenschr. 105:328-332. 